Artigos originais

Esta seção destina-se à publicação de artigos enviados espontaneamente pelos interessados

\title{
BIOÉTICA COMO CASUÍSTICA E COMO HERMENÊUTICA
}

\author{
José Roque Junges \\ Universidade do Vale dos Sinos - UNISINOS, São Leopoldo/RS,Brasil. \\ roquejunges@hotmail.com
}

Resumo: A bioética desenvolveu-se, no seu início, a partir do paradigma do principialismo proposto pela obra de Beauchamp e Childress, Principles of Biomedical Ethics. Mais aos poucos foram surgindo críticas à tirania dos princípios. A crítica mais contundente foi levantada por Jonsen e Toulmin com o livro The Abuse of Casuistry em que contrapõem ao principialismo o paradigma da casuística. Para eles, a metodologia adequada para a Bioética é a análise de casos e não a aplicação de princípios. Por isso tentam recuperar a importante e florescente casuística do início dos tempos modernos, libertando-a dos seus abusos. O artigo apresenta essa discussão, mostrando a importância da metodologia da análise de casos para a solução de problemas ao nível da ética clínica. Oferece as críticas ao paradigma da casuística, apontando para a necessidade da hermenêutica como corretivo dos seus possíveis excessos e desvios. Para não cair num puro convencionalismo moral é importante interpretar os pressupostos que fundamentam as soluções concretas. Por isso é conveniente que a bioética tenha duas faces complementares: uma casuística, para chegar a decisões práticas e eficientes; e outra hermenêutica, que traz à luz as pré-compreensões teóricas que sustentam essas decisões.

Palavras-chave: Casuística. Principialismo. Hermenêutica. Retórica. Taxionomia de casos.

\begin{abstract}
At the beginning, Bioethics grew up within the paradigm of Principialism, proposed by the book of Beauchamp and Childress, Principles of Biomedical Ethics, gradually appeared critics to the tiranny of principles. The most cutting critics was presented by the book of Jonsen and Toulmin, The Abuse of Casuistry where the authors set the paradigm of casuistry against the Principialism. The appropriate methodology to Bioethics is, for them, the analysis of cases and not the application of principles. They try to recuperate the important and flourish casuistry of the beginning modern time, setting free from his abuses. The article presents this discussion, showing the importance of the case analysis methodology to the solution of the clinic ethics problems. Offer the critics to the casuistry paradigm, pointing out the necessity of hermeneutic as corrective to his feasible excesses and diversions. To not falling in a pure moral convencionalism, it is important to interpret the presuppositions of the concrete solutions. Therefore it is suitable that the Bioethics would have two faces: one casuistic arriving to practical decisions and one hermeneutic lighting out the theoretical pre-comprehensions which sustain these decisions.
\end{abstract}

Key words: Casuistry. Principialism. Hermeneutic. Rhetoric. Taxionomy of cases. 
A

bioética surgiu como preocupação pelas incidências da intervenção tecnológica do ser humano no ambiente natural e como resposta aos dilemas éticos provocados pelas novas descobertas biológicas e pelos avanços da medicina sobre a saúde do ser humano. São as duas tradições que a bioética carrega em sua identidade: uma mais ecológica, legada por Potter; e a outra mais clínica, introduzida por Hellegers. A primeira assumiu mais a forma de crítica cultural do uso das biotecnologias e sua influência sobre o entorno natural e social. A segunda desenvolveu-se como busca de soluções práticas aos problemas enfrentados pelos profissionais na clínica e pelos cientistas nas pesquisas envolvendo seres humanos. Assim, podemos falar de duas faces da bioética: uma mais de cunho hermenêutico-crítico, que tenta interpretar os pressupostos culturais do uso das biotecnologias e outra mais casuística, que busca soluções concretas para os dilemas. Essas duas faces são epistemologicamente necessárias e exigem-se mutuamente.

\section{Bioética como Análise de Casos}

Os dilemas éticos concretos não podem ser afrontados com um discurso teórico, pois exigem soluções práticas e eficientes. Esse é o berço do surgimento da bioética: a análise de casos. No início da década de 1970, a opinião pública dos Estados Unidos ficou chocada com a revelação sobre o uso de pacientes fragilizados (sifilíticos negros, pacientes com Síndrome de Down e com diálise renal) no desenvolvimento de pesquisas sem o devido consentimento informado. Esses fatos, ao lado de outros, fizeram eclodir a consciência sobre os direitos dos pacientes e levaram o governo a criar uma comissão especial para estudar a questão.

Depois de quatro anos de discussão, a comissão publicou o Relatório Belmont, propondo os três princípios éticos básicos para o envolvimento de seres humanos em pesquisas: autonomia (necessidade do consentimento informado do envolvido); beneficência (atenção por parte do pesquisador aos riscos e benefícios para o envolvido) e justiça (busca de eqüidade quanto aos sujeitos de experimentação) (BELMONT REPORT, 1979). Segundo o relatório, esses princípios pretendem orientar os cientistas, os sujeitos de experimentação, os cidadãos interessados e os avaliadores à compreensão dos conceitos éticos inerentes à experimentação com seres humanos. Esses princípios, adquiridos indutivamente por meio da análise de casos, tornaram-se o núcleo central e o cerne de desenvolvimento da bioética. 


\section{Paradigma Principialista}

Embora os três princípios se refiram à pesquisa envolvendo seres humanos, ofereciam um ótimo esquema para renovar o conteúdo da ética médica, que já não respondia aos desafios postos pelos avanços da medicina. Esse foi o intento de Beauchamp e Childress ao publicarem, em 1979, o já clássico Principles of Biomedical Ethics (BEAUCHAMP \& CHILDRESS, 1979) que já está na sua quinta edição (BEAUCHAMP \& CHILDRESS, 2001) ${ }^{1}$, sendo continuamente revisado e melhorado com as críticas. Os autores construíram uma ética médica fundada nos princípios de autonomia, beneficência, nãomaleficência e justiça. A obra tornou-se um manual standard para o ensino da ética médica nos Estados Unidos, influenciando fortemente o paradigma principialista assumido pela bioética.

Trata-se de um discurso ético orientado por princípios que pretendem oferecer um esquema teórico de moral para a identificação, análise e solução dos problemas morais enfrentados pela medicina atual. Os princípios englobam certas considerações morais: obrigações de respeitar os desejos de pessoas competentes (respeito pelas pessoas ou pela sua autonomia); obrigação de não provocar dano aos outros, principalmente não matar nem tratar com crueldade (não-maleficência); obrigação de produzir benefícios para os outros (beneficência); obrigação de ponderar danos e benefícios (utilidade); obrigação de distribuir com eqüidade danos e benefícios (justiça); obrigação de manter promessas e contratos (fidelidade); obrigação de dizer a verdade (veracidade); obrigação de não revelar informações, de respeitar a privacidade e de proteger informações confidenciais (confidencialidade).

Alguns princípios são primários como a autonomia, a beneficência, a não-maleficência e a justiça; outros são derivados ou normas (fidelidade, veracidade, e confidencialidade). Os princípios estão intimamente relacionados com obrigações expressas em normas de ação, dependendo de certa compreensão teórica deontológica e originando juízos particulares que são seu verdadeiro objetivo. Trata-se de um discurso ético baseado na linguagem de obrigações e deveres aos quais correspondem direitos.

Por exemplo, os princípios da beneficência e não-maleficência regulam o juízo particular sobre a produção de benefícios e a remoção de males e sobre a ponderação de danos e benefícios, segundo uma compreensão utilitarista.

\footnotetext{
${ }^{1}$ A tradução brasileira pelas edições Loyola foi feita sobre a quarta edição (1994): Princípios de Ética Biomédica (Tradução de L. Pudenzi) São Paulo: Ed. Loyola, 2002.
} 
O princípio da autonomia orienta o juízo particular sobre situações que implicam decisões sobre a terapêutica a ser aplicada. Ele se expressa na obrigação normativa de respeitar o consentimento informado, um direito do paciente dependente de uma compreensão kantiana de liberdade. A autonomia adquiriu um lugar privilegiado frente aos outros princípios no paradigma principialista da bioética.

Beauchamp e Childress defendem que os princípios não são absolutos, mas prima facie, isto é, evidentes à primeira vista na consideração do caso, válidos e prescriptivos enquanto não aparecer outro princípio mais incisivo. Eles não se expressam em normas incondicionais, mas em máximas condicionadas. Essa é a maneira como os autores resolvem conflitos de princípios, freqüentes nas soluções principialistas de casos e alvo das críticas dos outros paradigmas.

A primeira edição da obra inseria-se na perspectiva do que se convencionou chamar de "Ética Aplicada" que é a aplicação de princípios universais aos casos particulares dentro de um raciocínio dedutivo. Nas seguintes edições a pura aplicação foi sendo corrigida pelo conceito de balanceamento de princípios, considerados prima facie e potencialmente passíveis de entrar em conflito em situações concretas, necessitando, por isso, de ponderação (BEAUCHAMP \& CHILDRESS, 1983). De um modo especial, a aplicação foi completada pelo conceito de especificação que é a tentativa de dar conteúdo aos princípios, especificando o seu significado, objetivo e alcance através da particularidade do caso. Nas últimas edições, a especificação adquire maior importância, mas ela não pode oferecer, segundo os autores, o modelo exclusivo para a relação entre o princípio e o juízo particular. (BEAUCHAMP \& CHILDRESS, 1994; BEAUCHAMP \& CHILDRESS, 2001). Em outras palavras, o princípio permanece como critério primário, ponto partida para a análise ética. Por isso pode-se falar segundo Degrazia de um "principialismo específico" (DEGRAZIA, 1992).

\section{Paradigma Casuísta}

O paradigma principialista recebeu críticas quanto ao método e quanto aos pressupostos que sustentam a proposta. A principal crítica quanto ao método é não dar primazia à particularidade do caso e insuficiente atenção às circunstâncias concretas, porque tem como critério e ponto de partida o princípio, concebido na sua universalidade abstrata, aplicado ao caso sin- 
gular. Essa crítica foi levantada e desenvolvida pelos casuístas que tentam opor-se a assim chamada por Toulmin "tirania dos princípios", recuperando o tradicional paradigma moral da casuística em moldes contemporâneos (TOULMIN, 1986). Esse foi o intento da importante obra de Jonsen e Toulmin, The Abuse of Casuistry que tenta retomar a dimensão essencialmente prática do conhecimento moral, que justamente se diferencia do conhecimento teórico pela sua particularidade (JONSEN \& TOULMIN, 1988). A obra provocou uma grande discussão, repercutindo positivamente no desenvolvimento da reflexão ética.

Jonsen e Toulmin foram membros da Comissão Belmont. Refletindo posteriormente sobre o trabalho realizado pela Comissão concluíram que o ponto de partida da discussão não foram os princípios, certamente fonte de possíveis divisões entre os membros com diferentes visões de moral, mas a análise de casos. A Comissão conquistou unanimidade porque não discutiu sobre teorias éticas, mas refletiu a partir de casos particulares, progredindo por meio da consideração das circunstâncias singulares e comparando com soluções já consagradas de casos, para assim chegar a conclusões. Os princípios arrolados pelo Relatório são as conclusões de um processo casuístico. Beauchamp e Childress tomaram esses princípios como base para a estrutura de sua obra, mas os interpretaram numa perspectiva abstrata e universal como normas prescriptivas, esquecendo o método pelo qual se atingiu esse conjunto de princípios. Essa constatação é a base da crítica de Jonsen e Toulmin ao paradigma principialista e, de uma maneira particular, à própria obra Principles of Biomedical Ethics.

\section{Origem do método casuístico}

Para Jonsen e Toulmin, apontar para a importância da análise de casos permite uma recuperação histórica do paradigma casuístico, libertando-o de seus abusos. Esse paradigma floresceu nos séculos XVI e XVII como resposta aos problemas morais do advento do mundo moderno com suas transformações culturais, econômicas, políticas e religiosas. Não se encontravam soluções no discurso tradicional da moral que era muito estreito para incluir a nova configuração de antigas questões como, por exemplo, a absoluta proibição do juro e da mentira, dois casos paradigmáticos naquela época. A pergunta central era se existem situações em que a cobrança de juros ou a ocultação da verdade é moralmente justificável? Para respondê-la era preci- 
so compreender a nova situação sócio-cultural em que aconteciam as transações comerciais, o jogo político, o procedimento jurídico penal etc. Era necessário partir da análise das circunstâncias concretas para entender os novos dilemas éticos e buscar a solução por comparação analógica com outros casos já conhecidos.

\section{Retórica e casuística}

Para Jonsen e Toulmin o paradigma clássico da casuística foi estruturado segundo o raciocínio da retórica. A retórica, em seu sentido mais geral, significava a arte de formular argumentos. Estritamente falando, não se pode construir argumentos antes de ter uma visão clara da questão presente no caso concreto. A razão retórica é a faculdade de descobrir o direcionamento da pergunta moral, fornecendo um caminho na procura do cerne da questão. Os recursos (topoi, segundo Aristóteles), usados pelo raciocínio retórico para chegar a esse cerne, podem ser aqueles comuns a qualquer área de conhecimento como a analogia, a proporção, a causalidade, o modo ou aqueles particulares de uma certa área de conhecimento, como por exemplo a ética: o princípio, a norma, o dever, a justiça, a virtude dentre outros.

Os tópicos particulares são sensíveis ao contexto. Eles são situados, especialmente, tratando-se de ética. Eles direcionam a construção da argumentação moral e a busca do cerne da questão ética. Os tópicos particulares do caso facilitam e fornecem a propedêutica da argumentação. Da análise dos topoi surge o que os retóricos chamavam de stasis, isto é, a questão que dá origem ao caso. Em outras palavras, manifesta-se o dilema ético. Exaurido levantamento da "topografia" moral (os topoi particulares), o cerne ético da questão torna-se relativamente claro, emergindo invariavelmente uma máxima moral que conclui a busca. Quando surge indutivamente a máxima, passa-se do âmbito específico para o universal. Mas essa máxima não pode ser congelada em sua abstração, precisa ser continuamente descongelada, remetendo-a à particularidade de novos casos.

Jonsen e Toulmin mostram que a construção do paradigma casuístico a partir do raciocínio retórico de Aristóteles e Cícero, foi obra dos jesuítas às voltas com a assessoria ética de pessoas implicadas nos novos dilemas morais daquela época. O método foi sendo discutido e burilado, dando origem a uma enorme quantidade de publicações sobre os diferentes problemas enfrentados pela consciência moral daquele tempo. É bom lembrar que a 
casuística estava inserida num paradigma mais amplo de teologia moral que fornecia o horizonte da reflexão ética e que foi um método de solução de casos que floresceu igualmente entre os pensadores éticos protestantes (NIGGAR, 1989), principalmente anglicanos (KIRK, 1999) como também entre judeus e muçulmanos.

\section{O abuso da casuística}

Assim como a mentalidade atual é acusada de levar ao relativismo moral, a casuística em sua época foi acusada de laxismo. Um método, inspirado pelo raciocínio retórico e com aderência às circunstâncias concretas na solução de casos, é sempre passível de exageros e originador de graves desvios, quando não bem compreendido. Aconteceram abusos nas mãos de autores inescrupulosos, abusos certamente não presentes na maioria de seus autores mais sérios. Por isso, Jonsen e Toulmin advogam no próprio título da sua obra The Abuse of Casuistry que é necessário apontar e criticar os abusos e não simplesmente condenar a casuística como método, o que aconteceu com a obra Les Provinciales de Blaise Pascal.

A casuística recebeu um golpe mortal na artística e irônica pena do jansenista Pascal que, como matemático, queria uma moral more geometrico que não se misturava com a particularidade das circunstâncias sub-lunares. Usando uma linguagem jornalística cativante, Pascal ridicularizou o método dos jesuítas, citando textos fora do contexto, exagerando argumentos delimitados e misturando propositadamente autores de diferentes procedências. Respondeu a uma tendência, típica da nascente modernidade, de buscar uma moral pura e incontaminada que se expressaria na formalidade da norma, cujo expoente máximo é a ética kantiana. Perderam-se, tanto a influência das inclinações interiores do caráter ou da virtude, quanto a consideração exterior das circunstâncias concretas do caso particular pelo discernimento da prudência, características do paradigma moral da alta Idade Média, encontradas especialmente em Tomás de Aquino.

Evidente que não se trata de simplesmente voltar à casuística do século XVI e XVII, mas deixando-se inspirar pelo método, tentar construir um paradigma contemporâneo de casuística. Esse é o louvável intento da obra de Jonsen e Toulmin, passível de críticas e necessitado de maior clarificação e especificação, acontecida posteriormente com o desenrolar da discussão provocou. 


\section{Casuística como Taxionomia de Casos}

Jonsen e Toulmin constróem uma proposta atualizada de casuística, como método apropriado para os comitês hospitalares, enfrentados com questões de ética clínica. O método apresenta-se como uma taxionomia de casos. Trata-se de comparar o caso necessitado de solução com casos paradigmáticos já resolvidos, até chegar a uma suposição de solução. O método de argumentação da casuística tem, segundo esses autores, vários níveis:

- A referência última da argumentação moral são certos casos paradigmáticos já consagrados: esses fazem surgir uma suposição inicial com peso de convencimento (máxima), na ausência de circunstâncias excepcionais. Trata-se do caso em que uma simples consideração moral tem peso e ajusta-se às circunstâncias sem lugar à dúvida ou ambigüidade (um exemplo é o caso da violência contra um inocente).

- Em casos problemáticos a primeira tarefa é decidir que casos paradigmáticos sustentam ou podem decidir as questões que se levantam (por exemplo, o caso do tratamento intensivo de neonatos com graves deformações genéticas).

- Um primeiro tipo de problema surge quando os casos paradigmáticos ajustam-se ambigüamente aos casos problemáticos atuais e a suposição criada está aberta a sérios questionamentos (por exemplo, é necessário sempre dizer a verdade ou existem situações que justificam a ocultação da verdade).

- Um segundo tipo de problemas surge quando dois ou mais casos paradigmáticos aplicam-se ao mesmo caso de uma maneira conflitiva e é necessário decidir entre eles (por exemplo, a gravidez ectópica, que põe em conflito a vida da mãe e a do feto, que foi resolvida pelo princípio de duplo efeito e hoje seria solucionada de outra maneira).

Na solução dos dois últimos casos, a solidez dos argumentos e sua relevância dependem de juízos substantivos: no primeiro caso o que significa dizer a verdade ao outro e, no segundo, qual é o peso moral em decidir por uma via ou outra. Esses juízos substantivos dependem da cultura e do período histórico. Assim, chega-se aos seguintes pontos:

- A história da prática moral em diferentes épocas e culturas mostra uma progressiva clarificação das exceções, que podem ser admitidas em relação à suposição moral básica. Por exemplo, um caso clássico eram as exceções à proibição da cobrança de juros ou à ocultação da verdade.

- Essa história mostra também uma progressiva extensão e elucidação 
dos casos paradigmáticos associados com aquela suposição moral. Eles fornecem o conteúdo para a suposição moral, por exemplo, da honestidade das relações econômicas e da veracidade das relações pessoais. Jonsen e Toulmin concluem que:

- O raciocínio moral prático, ainda hoje, ajusta-se melhor ao modelo retórico de argumentação (analogia de casos para chegar a uma máxima) do que aquele de demonstração geométrica (aplicação formal de princípios).

Ao contrário de metodologias teoricamente guiadas que se aproximam das situações particulares equipadas com um conjunto de princípios morais, a nova casuística insiste que o conhecimento moral deve desenvolver-se pela análise concreta de casos. Essa visão corresponde à diferença entre direito positivo e jurisprudência. Certas tradições jurídicas são mais baseadas no código legal, outras mais fundadas nas soluções dadas a casos concretos pela jurisprudência. Nesse sentido, a casuística apresenta-se como uma morisprudência.

Existe uma diferença fundamental de método entre a ética aplicada e a casuística. Para a primeira, os princípios não só servem de ponto de partida para as práticas, isto é, têm uma antecedência derivada da teoria antes da aplicação, mas também têm prioridade sobre as práticas, no sentido de justificar ou criticar as práticas. Essa prioridade lógica dos princípios sobre as práticas é o principal alvo das críticas à ética aplicada. Para a nova casuística, os princípios não são mais do que resumos de significados embebidos nas práticas. Por isso as práticas ou os casos paradigmáticos servem de ponto de partida e têm prioridade sobre os princípios. Os casos são o verdadeiro centro onde se dá a descoberta do sentido moral e da construção da certeza moral. Se para o método dedutivista os princípios pairam incontaminados sobre os fatos, para a nova casuística, ao contrário, os princípios estão sujeitos à revisão e articulação à luz dos novos casos.

\section{Pedagogia e casuística}

Para Jonsen e Toulmin, a casuística não só serve como um método adequado para resolver dilemas clínicos nas comissões de ética de hospitais, mas, principalmente, como pedagogia para ensinar bioética. A simples explicitação de princípios com alusões a casos hipotéticos provoca dormência mental nos alunos e não habilita a resolver futuros dilemas. Tomando em 
consideração as implicações pedagógicas da casuística, Arras apresenta algumas sugestões didáticas: 1 . Partir de casos reais e não hipotéticos, pois os reais são complexos, intrincados e sem uma ordem pré-fixada, enquanto os hipotéticos geralmente são inventados para ilustrar o princípio teórico, não sendo, na verdade, um dilema; 2 . Escolher casos com muitos e variados detalhes, pois a verdade moral surge justamente a partir dos detalhes; 3. Não analisar um caso isolado, mas uma seqüência de casos análogos e paradigmáticos para, assim, captar o tipo de raciocínio ético e como o significado dos assim chamados princípios aparece nos detalhes dos casos sucessivos; 4. Aprender a fazer diagnóstico moral, isto é, captar o tipo de questão ética presente no caso a resolver o que exige imaginação, interpretação e discernimento para descobrir do que se trata (ARRAS,1991).

\section{Críticas à casuística}

O surgimento da nova casuística foi importante porque questionou a mantra em que se transformaram os três princípios da bioética, recuperou a compreensão antiga de que o conhecimento moral é essencialmente particular e criticou o modelo geométrico subjacente ao paradigma principialista, acentuando a dimensão contingente e prática da sabedoria ética identificada com a fronesis aristotélica (discernimento da particularidade do ato) e não com episteme (ciência universal e abstrata). Essa crítica foi tão importante que as sucessivas edições do Principles of Biomedical Ethics procuraram integrar a consideração dos princípios (modelo aplicativo) com a análise dos casos (modelo casuístico) num modelo integrado, chamado por Beauchamp e Childress de Coherence Theory, sem negar contudo a prioridade dos princípios (BEAUCHAMP \& CHILDRESS, 2001). ${ }^{2}$

Se a recuperação da sabedoria prática da taxionomia de casos contra a onipotência geométrica dos princípios foi importante, o paradigma casuístico não deixa de ter seus problemas. Os pontos fracos do paradigma principialista são os pontos positivos da casuística e os pontos fortes da consideração dos princípios são os aspectos negativos da análise de casos.

A primeira questão é o que determina um caso, o que faz escolher um ou

\footnotetext{
${ }^{2}$ No último capítulo da quinta edição, (2001) aparece a diferença entre os Top-Down Models (p. 385) que partem de princípios e os Bottom-up Models (p. 391) que privilegiam a análise de casos e uma tentativa de integração na Coherence Theory (p. 397).
} 
outro, ou uma seqüência deles. Não é suficiente a casuística mostrar como interpretar casos. Antes de apresentar uma agenda de casos deve-se pensar sobre o critério para selecionar os casos a serem moralmente escrutinados. A agenda pode corresponder a uma visão predominantemente masculina, excluindo, por exemplo, casos e dilemas importantes para a perspectiva feminina do cuidado. Deve-se considerar que não só a identificação dos casos, mas a própria especificação dos mesmos não é isenta de pressupostos. Nesse sentido, a casuística também não pode pretender ser isenta de teoria.

Os casuístas alegam que progridem moralmente, indo de um tipo de caso a outro na solução de dilemas, sem ajuda de qualquer princípio ou aparato teórico. Essa visão de uma percepção epistemologicamente imaculada corresponde a uma concepção ultrapassada de ciência, consideração especialmente pertinente depois da teoria dos paradigmas de Kuhn (KUHN, 1962). Não existe a possibilidade de uma observação de fatos, teoricamente isenta. Pois todo conhecimento engloba interesses que dependem de uma determinada visão do ser humano, da sociedade e do mundo.

Pressupostos teóricos determinam a seleção dos casos, princípios de relevância explicam a relação entre os casos, apontando qual é o fio que liga um caso a outro numa seqüência. Sem um princípio de relevância, os casos se dispersariam em diferentes direções sem coerência interna. Nesse sentido, existe uma necessária condição prévia para estabelecer qualquer taxionomia moral de casos. Por outro lado, os casos de tratamento de comatosos ou os fetos com graves deformações genéticas, as doações de órgãos de neonatos anencefálicos ou de acidentados com previsão de morte, necessitam definir o conceito de morte, o estatuto moral do feto, a natureza da personalidade, o que significa respeitar e como conjugar a relativa importância de atingir conseqüências benéficas e o tratamento dos seres humanos como fins. Tudo isso depende de uma compreensão teórica que os casuístas não podem ignorar.

É ingênuo, por outro lado, pensar que o método casuístico chega a um consenso simplesmente pela taxionomia dos casos. Vivemos uma cultura moral cindida numa multiplicidade de significados que configuram uma diversidade de valores, muitas vezes em conflito. O método casuístico não pode querer resolver esse conflito de interpretações das práticas que certamente influencia a análise do caso. Ele não tem condições para ajudar a desenvolver uma interpretação mais coerente que possa basear o consenso ético da sociedade. A nova casuística não é um instrumento adequado para gerar consenso num mundo fraturado pelo conflito de valores. Tampouco a pura teoria ética pode pretender garantir esse consenso. Cresce a consciência de que para atingir 
certo consenso moral não se pode fugir da tarefa de interpretar os significados embebidos em nossas práticas sociais, instituições e história.

A crítica mais radical ao método casuístico é que ao resolver um novo caso ou dilema com a taxionomia de soluções já estabelecidas, origina um conservadorismo social e um convencionalismo ético. A casuística não confronta criticamente, mas refina os "pré-conceitos" estabelecidos. Falta criticidade ao paradigma casuístico em dois sentidos: por um lado, sustenta significados culturais estabelecidos, faltando distanciamento para formular críticas a essas compreensões sociais e, por outro, ignora as relações de poder (principalmente econômicos) presentes nesses significados culturais, que distorcem a comunicação e, nesse sentido, a interpretação. Por isso, a casuística deve ser sempre completada com o que Habermas chamou de uma teoria crítica das relações sociais (HABERMAS, 1982) ou, nas palavras de Ricoeur, por uma "hermenêutica da suspeita" (RICOEUR, 1969).

A ética aplicada foi acusada de desenvolver uma bioética excessivamente individualista, mas a casuística não é um remédio para essa deficiência do principialismo. O método casuístico pode antes exacerbar o individualismo predominante na atual reflexão bioética, porque ao solucionar conflitos de direitos de indivíduos, não responde a dilemas de políticas de saúde pública ou a direitos sociais de comunidades. Por isso necessita ser complementado com uma visão comunitarista.

O método casuísta confia mais na habilidade interna daquele que analisa os casos do que na orientação externa dos princípios. Um caso ou uma seqüência de casos correlacionados não são um dado bruto, mas, no fundo, uma construção do casuísta e, por isso, dependente, por um lado, de pressupostos teóricos, mas, de outro, também da destreza intelectual e moral do casuísta. Essa habilidade interna adquirida é o que a tradição chamou de virtude. Ela é um hábito operativo, adquirido pela experiência moral, que habilita a agir de acordo com esse hábito. A virtude básica, segundo a tradição aristotélica-tomasiana, é a prudência que permite a discernir as circunstâncias particulares de um ato moral. A casuística tradicional estava inserida no contexto moral do paradigma da virtude. Portanto, a habilidade intelectual e moral para discernir o concreto é necessária para o método casuísta. Por isso o paradigma casuísta precisa ser complementado com a perspectiva da virtude. Não é por nada que a questão do caráter moral adquire sempre maior importância na reflexão ética. A consideração da virtude foi assumida tanto pela perspectiva principialista em Beauchamp e Childress (BEAUCHAMP \& CHILDRESS, 2001) quanto pela casuísta em Devettere (DEVETTERE, 2000). 


\section{Casuística e juízo particular}

Embora levando em consideração as críticas e tendo presente os necessários complementos, o paradigma casuísta é o método mais apropriado para solucionar casos. Significa partir da análise acurada e performativa das circunstâncias particulares do caso, para poder detectar o cerne moral da questão. Para chegar a esse cerne, ajuda a comparação com casos analógicos já resolvidos. Dessa análise e interpretação emerge a máxima ou o princípio que deve orientar o agir como solução ao caso.

Não se pode resolver problemas morais aplicando simplesmente princípios universais abstratos, porque o conhecimento moral diz respeito a realidades particulares contextuadas. A sua certeza, por isso, é moral, isto é, contingente e não metafísica ou geométrica, ou seja, absoluta. O método casuísta é característico do próprio exercício clínico, porque não existem doenças universais e abstratas, mas o médico precisa descobrir a particularidade da enfermidade nesse paciente singular. Por isso faz uma anamnese dos sintomas particulares, compara com o quadro sintomático de casos similares, chegando a um juízo clínico pelo discernimento das circunstâncias.

A doença não é um problema técnico que puros exames laboratoriais e computadorizados podem resolver; ela é um evento pessoal que para ser afrontado necessita, antes de mais nada, de comunicação humana. Nessa relação, a doença torna-se uma narrativa singular a ser interpretada casuisticamente. Se a doença e a saúde dos seres humanos e a vida em geral dos seres vivos são realidades essencialmente complexas e dependentes de inter-relações, elas não podem ser compreendidas a partir de puras teorias e como objetos das técnicas, mas necessitam de uma atitude de sabedoria e discernimento ético, característicos da casuística. Nesse sentido, a casuística revela-se o método apropriado para solucionar problemas éticos implicados na doença, na saúde e na vida em geral.

\section{Bioética como Interpretação de Pressupostos}

Na crítica ao paradigma casuísta, já aparece a necessidade de detectar os pressupostos que estão determinando a interpretação do caso. Nesse sentido, a hermenêutica é um complemento necessário da casuística para que não esteja a serviço de um convencionalismo ético-cultural e do conservadorismo econômico-político. Por isso, a hermenêutica torna-se uma 
dimensão essencial à própria bioética, porque essa não pode ser reduzida a simples solução de dilemas e casos. Ela precisa desenvolver uma hermenêutica da suspeita que interpreta os pressupostos éticos, antropológicos e sócio-culturais, que determinam a maneira como realidades relacionadas com a vida e a saúde são compreendidas e tratadas na cultura e sociedade atuais. Nesse sentido, a bioética torna-se teoria crítica por sua dimensão hermenêutica, como propõe Leder (LEDER, 1994).

A hermenêutica assumiu, no século XX, um papel central na dinâmica do pensamento humano, por obra principalmente de Heidegger e Gadamer. Heidegger mostrou que a hermenêutica não é apenas um setor do conhecimento, mas tem um significado ontológico (HEIDEGGER, 1988). O fato de interpretar é uma dimensão do ser humano enquanto tal. Todo conhecimento humano é interpretativo. Ler um texto antigo ou atual, contemplar um campo visual ou uma obra de arte, analisar dados científicos do laboratório ou dados criminais do processo jurídico, mirar os traços da face ou acolher um gesto de carinho da pessoa amiga, são todas ações interpretativas, porque se trata de dar significado a essas realidades ("textos"). Essa interpretação depende de pressupostos que configuram o significado.

Gadamer sugere que toda interpretação é necessariamente pré-conceituada (GADAMER, 1997). Isso não tem um sentido pejorativo, mas indica que nos aproximamos de qualquer "texto" com pré-juízos ou pré-compreensões criados por nossa história pessoal e cultural e pelos interesses pragmáticos que canalizam e determinam a leitura interpretativa. Essa contextualidade do conhecimento sustenta o que esse autor e seus predecessores chamaram de "círculo hermenêutico".

Essa circularidade hermenêutica expressa a estrutura da compreensão que sempre é uma apreensão de sentido por parte do sujeito, a qual depende do horizonte contextual cognitivo. Assim, a compreensão depende de pré-compreensões do sujeito, presentes neste horizonte, que geralmente não estão explicitadas, mas influenciam a apreensão de sentido. Portanto, todo conhecimento é sempre situado, e sua objetividade seja decorrência da explicitação das pré-compreensões do sujeito, presentes no seu horizonte de compreensão.

Se as pré-compreensões são centrais para entender o produto do conhecimento humano, é importante trazê-las à luz e submetê-las à análise e explicitação. Se isso é determinante para a seriedade e coerência de qualquer tipo de conhecimento, muito mais para a bioética, um saber que pretende salvaguardar bens básicos para a vida humana e o entorno natural. Por isso é importante interpretar as pré-compreensões que influenciam a maneira de a 
bioética afrontar os problemas éticos do exercício da medicina, do uso das biotecnologias, da intervenção no ambiente natural. Essas pré-compreensões podem ser pressupostos éticos (visões de ética e de moralidade), antropológicos (compreensão subjacente de ser humano) e sócio-culturais (contexto social e valores culturais).

Se a bioética se reduz a buscar soluções práticas para dilemas éticos da medicina sem refletir sobre questões mais básicas, ela pode tender a justificar o status quo e ser um simples reflexo do ambiente cultural, perdendo o que é característico de qualquer reflexão ética: ser uma crítica dos costumes. Nessa perspectiva, a bioética assume o papel de crítica sócio-cultural. O perigo é reduzir a bioética a uma espécie de "capelão da corte real da ciência". Nas palavras de Campbell este é o papel da bioética hermenêutica:

"Significaria que a bioética nunca teria realmente uma visão crítica do progresso científico, mas procuraria, tão somente, moderar seus efeitos adversos ao sugerir diretrizes para sua aplicação. Parece ser um papel por demais passivo e que trai o dever da filosofia de levantar perguntas fundamentais sobre a natureza do conhecimento e sobre os fundamentos de noção de bondade e maldade. Precisamos elaborar uma bioética sadiamente crítica a respeito da ciência e que ao mesmo tempo reconhece seus potenciais benefícios" (CAMPBELL, 1998).

\section{Considerações Finais}

As duas faces da bioética são necessárias e exigem-se mutuamente. Os comitês institucionais pautam-se no dia-a-dia por uma bioética casuística, porque precisam responder a dilemas éticos concretos e urgentes. Mas, seria importante realizar periodicamente seminários de estudo e discussão sobre os temas fundamentais, nos quais devem ser explicitadas as pré-compreensões que servem de pressupostos às decisões tomadas. É o momento da bioética hermenêutica. Se isto é importante para um comitê institucional, muito mais para um Conselho Nacional de Bioética como acontece, por exemplo, no Comitê Consultativo Nacional de Ética para as Ciências da Vida da França, que publicou vários documentos de consenso, frutos de longas discussões hermenêutica. Um conselho de âmbito nacional tem como atribuição não apenas produzir recomendações sobre questões pontuais, mas também discutir mais amplamente teses e proposições de fundo. 


\section{Referências bibliográficas}

ARRAS, J. D. Getting down to cases: the revival of casuistry in bioethics. Journal of Medecine and Philososphy vol. 16: 29-51, 1991.

BEAUCHAMP, T. L. \& CHILDRES, J. F. Principles of Biomedical Ethics. New York: Oxford University Press, 1979.

BEAUCHAMP, T. L. \& CHILDRES, J. F. Principles of Biomedical Ethics (Second Edition). New York, Oxford University Press, 1983.

BEAUCHAMP, T. L. \& CHILDRES, J. F. Principles of Biomedical Ethics (Fourth Editon). New York, Oxford University Press, 1994.

BEAUCHAMP, T. L. \& CHILDRES, J. F. Principles of Biomedical Ethics (Fifth Editon). New York, Oxford University Press, 2001.

BEAUCHAMP, T. L. \& CHILDRES, J. F. Princípios de Ética Biomédica. São Paulo, Ed. Loyola, 2002.

THE BELMONT REPORT. Ethical Principles and Guidelines for the Protection of Human Subject of Research. National Commission for the Protection of Human Subject of Biomedical and Behavioral Research. In: Encyclopedia of Bioethics. Warren Thomas Reich. (Editor In Chief), Georgetown University Macmillan, New York, 1979.

CAMPBELL, A. V. A bioética do século XXI, O Mundo da Saúde vol. 22, n. 3: 173, 1998.

DEGRAZIA, D. Moving forward in bioethical theory: theory cases and specified principlism, Journal of Medecine and Philosophy vol. 17: 511-539, 1992.

DEVETTERE, R. J., Practical Decision Making in Health Care Ethics: cases \& concepts. (Second Edition) Washington, Georgetown University Press, 2000.

GADAMER, H.-G. Verdade e Método:traços fundamentais de uma hermenêutica filosófica. Petrópolis, Vozes, 1997.

HABERMAS, J. Theorie des kommunikativen Handelns. Band I: handlungsrationalität und gesellschaftliche rationalisierung; Band II: zur kritik der funktionalistischen vernunft. Frankfurt A.M., Suhrkamp Verlag (Zweite Auflage), 1982.

HeIDEGGER, M. Ser e Tempo. (segunda edição) Petrópolis, Ed. Vozes, 1988.

JONSEN, A. R. \& TOULMIN, S., The Abuse of Casuistry: a history of moral reasoning. Berkeley / Los Angeles, University of California Press, 1988.

KIRK, K. E. Conscience and Its Problems: an introduction to casuistry. Louisville, Westminster John Knox Press, 1999.

KUHN, T. S. The Structure of Scientific Revolutions. Chicago, Chicago University Press, 1962.

LEDER, D. Toward a hermeneutical bioethics. In: Dubose, E. R., Hamel, R. P., 
Revista Brasileira de Bioética

O'Connell, L. J. (Eds.), A Matter of Principles? Ferment in U.S. Bioethics. Valley Forge (Pe), Trinity Press International: 240-259, 1994.

NIGGAR, N., A case for casuistry in the church, Modern Theology vol. 6, n. 1: 29$51,1989$.

RICOEUR, P. Le Conflit des Interprétations, Paris, Le Seuil, 1969.

TOUlMiN, S. The Tiranny of Principles, Hastings Center Report vol. 11: 31-39, 1981.

Recebido em 8/4/2005

Aprovado em 22/4/2005 